\title{
Identifying Pigmentation-Related Genes in Ophiostoma piceae Using Agrobacterium-Mediated Integration
}

\author{
Philippe Tanguay, Kristin Tangen, and Colette Breuil
}

Department of Wood Science, University of British Columbia, 2424 Main Mall, Vancouver, V6T 1Z4, Canada. Accepted for publication 5 April 2007.

\begin{abstract}
Tanguay, P., Tangen, K., and Breuil, C. 2007. Identifying pigmentationrelated genes in Ophiostoma piceae using Agrobacterium-mediated integration. Phytopathology 97:1040-1048.

Wood sapstain, a cosmetic defect that results in significant economical loss to forest-products industries, is caused by mycelial melanization of the wood-colonizing ophiostomatoid fungi. To improve our understanding of how melanin biosynthesis is regulated in the cosmopolitan sapstaining fungus, Ophiostoma piceae, we used insertional mutagenesis. Insertional mutants were generated by restriction enzyme-mediated integration (REMI) and Agrobacterium-mediated integration (AMI). We screened 1,053 REMI and 1,083 AMI transformants and found 30 mutants with impaired growth or pigmentation. We characterized four AMI transfor-

mants in more detail, in which the T-DNA integrated at a single locus. The albino mutant TOPA45 had incorporated the T-DNA in a polyketide synthase gene (PKS1). The mutants TOPA1 and TOPA1076 displayed reduced pigmentation. In TOPA1, the T-DNA was inserted into a gene that encodes a putative protein kinase activator whereas, for TOPA1076, it was inserted into a gene that encodes a protein with unknown function. Finally, the vegetative hyphae of mutant TOPA814 were not melanized, whereas the synnemata displayed the same level of pigmentation as the wild type. In the TOPA814 mutant, segregation analysis revealed that the mutant phenotype was not linked to the T-DNA insertion locus but to a translocation from the PIGl locus to the left border of the T-DNA. The protein predicted for the PIG1 locus had a middle homology region that was specific to fungal transcription factors.
\end{abstract}

Sapstain is a widespread, economically significant cosmetic wood defect. The discoloration is caused by pigmented hyphae of fungi from the genera Ophiostoma, Ceratocystis, and Leptographium that have colonized logs, lumber, and trees (41). Zink and Fengel were the first to show that the staining pigment was melanin in hyphal cell walls and sheaths (60-62). Although fungal melanin can be synthesized by three main pathways, glutaniminyl-4-hydroxybenzene (GHB), catechol, and 1,8 dihydroxynaphthalene (DHN) $(3,9)$, sapstaining fungi appear to use the DHN pathway $(16,21)$. In this pathway, acyl CoA precursors are cyclized by polyketide synthase (PKS1) to form 1,3,6,8-tetrahydroxynaphthalene, which is reduced by tetrahydroxynaphthalene reductase (THR1) to scytalone. Scytalone dehydratase (OSD1) dehydrates scytalone to form 1,3,8-trihydroxynaphthalene, which is reduced to vermelone by 1,3,8-trihydroxynaphthalene reductase (THN2). Vermelone is converted to DHN by a second dehydration reaction. Finally, DHN monomers are polymerized to form DHN-melanin (3). Although the genes involved in DHN-melanin biosynthesis are well characterized in many ascomycetes (9), including ophiostomatoid fungi, little is known about the mechanisms by which DHN-melanin production is regulated.

Melanins are secondary metabolites and the regulatory mechanisms controlling the biosynthesis of many fungal secondary metabolites have been characterized (56). Although most of this work featured fungal toxin pathways, some of the findings may be applicable to the regulation of DHN-melanin biosynthesis.

Corresponding author: C. Breuil; E-mail address: colette.breuil@ubc.ca

* The $\boldsymbol{e}$-Xtra logo stands for "electronic extra" and indicates that the online version contains supplemental material not included in the print edition. Figure 1 appears in color online.

doi:10.1094/PHYTO-97-9-1040

(C) 2007 The American Phytopathological Society
Experimental data for regulatory mechanisms of this pathway have been reported in only a few fungal species. In the plant pathogen Colletotrichum lagenarium, CMK1, a gene encoding a mitogen-activated protein (MAP) kinase regulates PKS1 and SCD1 (homolog of Ophiostoma floccosum OSD1) genes during conidial germination; a $c m k l$ null mutant failed to synthesize melanin in appressoria (42). In C. lagenarium and the rice pathogen Magnaporthe grisea, two transcription factors have been identified that regulate genes in the DHN-melanin pathway: CMR1 and PIG1, respectively. Both transcription factors contain two distinct DNA-binding motifs: a Cys2His2 zinc finger motif and a $\mathrm{Zn}$ (II) 2Cys6 binuclear cluster motif (48). CMR1 regulates the biosynthetic structural genes coding for SCD1 and THR1 during mycelial melanization. More recently, in the phytopathogenic fungus Bipolaris oryzae, results suggest that near UV radiation upregulated the putative transcriptional activator gene $B M R 1$, which regulates the DHN-melanin pathway genes $P K S 1$, $3 H N R$, and SDI (25).

$O$. piceae, a globally distributed softwood sapstaining fungus, is an appropriate model organism for characterizing genetic regulatory mechanisms in melanin production. First, whereas other sapstaining fungi seem to produce melanin constitutively, in O. piceae, melanin biosynthesis occurs in particular life cycle phases in response to intrinsic or environmental signals (e.g., nutritional factors) $(14,17)$. O. piceae localizes melanin in phasespecific conidiophores, vegetative hyphae, and perithecia. This suggests that melanin biosynthesis involves transcription factors that interact with biochemical pathways related to development. In addition, $O$. piceae is amenable to genetic and molecular manipulation. It grows well in a variety of liquid or solid substrates, including agar-based media and wood. It is a heterothallic species that can be crossed easily with compatible mating partners, enabling genetic analyses of mutations and studies of genetic linkage (7). Significantly, O. piceae easily can be transformed using protoplasts or Agrobacterium spp. $(45,53)$. Its trans- 
formability prompted us to evaluate insertional mutagenesis as a tool for identifying the genetic factors that regulate its melanin biosynthesis.

In fungi, insertional mutagenesis is performed mainly by two procedures: restriction enzyme-mediated integration (REMI) and Agrobacterium-mediated integration (AMI). In REMI, fungal protoplasts are transformed with linearized plasmid DNA in the presence of a restriction endonuclease that generates compatible DNA ends. REMI's advantages include high plasmid-integration frequencies at the corresponding restriction sites in the genome, single-copy insertion, and random integration (24). In contrast, AMI relies on the ability of the soil bacterium Agrobacterium tumefaciens to deliver its T-DNA into fungal cells. AMI's advantages include transformation of intact cells (conidia) rather than protoplasts, random insertion, and single-copy integration (34). AMI has been widely used for gene tagging in plants, and recently was shown to be effective for insertional mutagenesis in yeasts and filamentous fungi $(8,34)$.

In this work, we assessed REMI and AMI as tools for identifying novel genes required for melanization in $O$. piceae. We present the results of an insertional mutagenesis screen and characterize four AMI-generated pigmentation-defect mutants.

\section{MATERIALS AND METHODS}

Isolates, media, and transformation. The $O$. piceae isolate AU55-3 (MAT A) was used for insertional mutagenesis. Isolate AU123-142 (MAT B) was used to perform sexual crosses directly on sapwood blocks. Progeny were retrieved as described by Bernier and Hubbes (4). REMI and AMI were performed using genetic transformation protocols described by Tanguay and Breuil (45). Plasmid pCB1004 (10) was used for REMI, and plasmids pAD1624, pAD1625, pBHt2, and pKHt $(1,38)$ were used for AMI.

A sample of purified scytalone was obtained from Michael Wheeler (Southern Plains Agricultural Research Center, United States Department of Agriculture-Agricultural Research Service). Scytalone also was prepared by the method of Kubo et al. (28) with some modifications. Briefly, a culture filtrate from potato dextrose broth (BD, Oakville, ON, Canada) of $C$. lagenarium strain $9201 \mathrm{Y}$ was adjusted to $\mathrm{pH} 5.0$ with $\mathrm{H}_{3} \mathrm{PO}_{4}$, saturated with $\mathrm{NaCl}$, and extracted with ethyl acetate. The solvent was rotoevaporated; then, the oily residue was purified by preparative thin-layer chromatography (TLC) as described by Bell et al. (2). The TLC band corresponding to scytalone was scraped off with a razor blade, purified on silica gel chromatography column, eluted in ethyl ether, crystallized with an equal volume of hexane, dried under $\mathrm{N}_{2}$, quantified by TLC, and resuspended in $95 \%$ ethanol. To determine whether mutants could metabolize scytalone into melanin, $100 \mu \mathrm{g}$ of the purified scytalone was spotted on a nitrocellulose disk, air dried, and placed at the edge of a fungal colony growing on potato dextrose agar (PDA).

Sapwood block assay. Blocks of 3.0 by 1.5 by $0.5 \mathrm{~cm}$ were cut from fresh sapwood extracted from a healthy 60-year-old lodgepole pine (Pinus contorta var. contorta), ion beam sterilized (Iotron, Port Coquitlam, BC, Canada), and frozen until needed. For the wood assay, the sapwood block was placed over a wet Whatman no. 3 filter paper and two layers of plastic mesh, and inoculated with a mycelium plug of each transformant. Phenotypes were assessed after 1 month of growth at room temperature. Mutant macromorphological characteristics that included wood block discoloration (sapstain), presence of fertile synnemata, and vegetative hyphae at the surface of the wood were compared to those of the wild-type isolate AU55-3.

Sporulation and vegetative growth. For yeastlike cells, $1 \times$ $10^{7}$ conidia from a 7-day-old culture were inoculated to $50 \mathrm{ml}$ of fresh complete medium (5), and the culture was shaken at 200 revolutions $\mathrm{min}^{-1}$ for 4 days at $22^{\circ} \mathrm{C}$ in darkness. The number of yeastlike cells was determined for three replicate cultures per isolate. For vegetative growth, isolates were inoculated centrally onto 2\% malt extract agar (MEA) (33 g of MEA supplemented with $10 \mathrm{~g}$ of technical agar per liter) (Oxoid Company, Nepean, ON, Canada) using 6-mm mycelial plugs. Two colony diameters were measured at right angles after 3 and 10 days of incubation at $22^{\circ} \mathrm{C}$ in the dark. The growth rate was determined for five replicates for each isolate. Yeastlike cell counts were logarithmically transformed to provide normal distribution. The data were subjected to analysis of variance. The statistical analyses were performed using the JMP IN software (JMP, version 6; SAS Institute Inc., Cary, NC). Differences were considered significant at $P$ values of $<0.05$.

DNA extraction and blotting. For Southern blotting and polymerase chain reaction (PCR), DNA was extracted following Möller's protocol (36). For preparation of the genomic DNA library, high molecular weight DNA was extracted from AU55-3 protoplasts prepared as described previously (45). Briefly, $O$. piceae yeastlike cells were enzymatically stripped of cell walls and the resulting protoplasts were lysed in $25 \mathrm{ml}$ of a solution containing 0.5 M Tris- $\mathrm{HCl}$ ( $\mathrm{pH} 8.0$ ), 0.5 M EDTA (pH 8.0), 3\% (wt/vol) sarkosyl, and proteinase $\mathrm{K}$ at $0.4 \mathrm{mg} / \mathrm{ml}$. Total genomic DNA was extracted with phenol/chloroform/isoamyl alcohol (25:24:1) and precipitated with isopropanol. The pellet was washed with $70 \%$ ethanol, resuspended in Tris-EDTA buffer, and partially digested with Sau3AI. The DNA fragments were size-fractionated on a sucrose gradient and cloned into lambda vector DASHII having compatible BamHI ends following the manufacturer's instructions (Stratagene, La Jolla, CA). Genomic DNA fragments flanking the insertion site of plasmids pBHt2 and pAD1625 were recovered by inverse PCR. Briefly, $5 \mu \mathrm{g}$ of genomic DNA was digested with restriction enzymes, purified on Qiaspin columns (Qiagen, Mississauga, ON, Canada), self-ligated overnight at $4^{\circ} \mathrm{C}$ using T4 DNA ligase (New England Biolabs, Pickering, ON, Canada), and amplified by PCR with "elongase" (Invitrogen, Burlington, ON, Canada) using the inverse PCR primers mentioned in the upper half of Table 1.

DNA sequencing. Bam HI fragments from candidate lambda DNA clones were subcloned into pBluescript II vector (Stratagene) and amplified in Escherichia coli DH5 $\alpha$. DNA sequences were generated from both strands by primer walking using plasmid DNA as template and ABI PRISM BigDye V3.1 chemistry (Applied Biosystems, Streetsville, ON, Canada). Sequencing was performed on an Applied Biosystems Prism 373 DNA sequencer at the UBC Nucleic Acid and Protein Service Laboratory (University of British Columbia, Vancouver, Canada).

Real-time reverse-transcription PCR. Total RNA isolation, cDNA synthesis, and real-time reverse-transcription (RT)-PCR experiments were performed as described by Tanguay et al. (44). Real-time RT-PCR data were generated using iQ SYBR Green

TABLE 1. Primers used in this study

\begin{tabular}{ll}
\hline Application, primer $^{\mathrm{z}}$ & \multicolumn{1}{c}{ Sequence } \\
\hline $\begin{array}{l}\text { Inverse PCR } \\
\text { RBF }\end{array}$ & 5'-CAGGCCCACAACAGCTACCAGT-3' \\
RBR & 5'-GAGCGAATTTGGCCTGTAGACCT-3' \\
RB2F & 5'-TCGTTTCCCGCCTTCAGTTTA-3' \\
RB2R & 5'-GGGGATGTGCTGCAAGGCGATTA-3' \\
LB3F & 5'-GCCTTGATTTCGCCATTCCCAGA-3' \\
LB3R & 5'-AAGCCCCCATTTGGACGTGAA-3' \\
Real-time RT-PCR & \\
PKS1-F & 5'-TGGGAAGACATCACGAAGCATGA-3' \\
PKS1-R & 5'-CATCAGGACAGCCTGTGTTG-3' \\
OSD1-F & 5'-CAGATCGATTACCGGTCGTT-3' \\
OSD1-R & 5'-GACGTTGGGGTCCGAGAT-3' \\
TUB-F & 5'-CCAGAGGCCTCGTTGAAGTA-3' \\
TUB-R & 5'-CCTTGACAGCAATGGCGT-3' \\
\hline
\end{tabular}

${ }^{\mathrm{z}} \mathrm{PCR}=$ polymerase chain reaction and $\mathrm{RT}=$ reverse transcription. 
supermix (Bio-Rad, Mississauga, ON, Canada) and fluorescence emissions were detected with an Mx3000P Real-Time PCR system (Stratagene). Data were analyzed using the $2^{-\Delta \Delta C t}$ relative quantification method in the instrument's software. Expression of PKS1 and SCD1 was normalized to an internal reference gene ( $\beta$ tubulin gene) in both the mutants and in AU55-3. The primers used for real-time RT-PCR are described in the lower half of Table 1.

\section{RESULTS}

We generated 1,053 hygromycin B (HMB)-resistant transformants using REMI and 1,083 $H M B$-resistant transformants through AMI. The transformants were inoculated onto sapwood blocks and phenotypic changes occurring in pigmentation and growth were examined. We selected 30 morphological mutants (17 REMI and 13 AMI) that displayed either reduced growth or altered (more or less) pigmentation when compared with the parental isolate AU55-3. Southern blot analysis showed that the plasmid was integrated into the genome of all the mutants. Transgene insertion at multiple loci occurred in 12 of the 17 REMI mutants, whereas all AMI mutants had single insertion loci (data not shown). We further characterized four AMI mutants (TOPA1, TOPA45, TOPA814, and TOPA1076) that had pigmentation defects and single-locus insertions.

Pigmentation on wood. Eight replicates for each selected mutant were inoculated onto sapwood blocks and grown for a month (Fig. 1A). The eight replicates showed homogeneous phenotypes. Given this uniformity, our results suggested that the mutant phenotypes were triggered by genetic traits rather than exogenous environmental factors. Mutant TOPA1 showed less pigmentation than the wild type; its mycelial mat on the wood surface was dense and fluffy, but it produced no conidiophores (synnemata). TOPA45, an albino mutant, had colorless vegetative hyphae and synnemata. TOPA814 showed reduced pigmentation; it had fertile and well-formed synnemata, but its vegetative hyphae on the wood surface were not melanized. Mutant TOPA1076 showed reduced pigmentation, which appeared to result from less mycelium and synnemata being produced on the surface of the sapwood block compared with the wild-type isolate AU55-3. Moreover, all the synnemata produced by TOPA1076 were stunted and sterile.

Pigmentation, sporulation, and growth in liquid and on malt extract agar. Morphological characteristics of the $O$. piceae wild type and mutants grown on MEA and PDA are shown in Figure 1B and C. Morphological differences were observed easily on agar media. For example, when a conidial suspension was spread onto PDA, no synnemata were produced, which facilitated the observation of reduced mycelial pigmentation for TOPA814 (Fig. 1B). We also examined the effects of each mutation on the production of yeastlike cells and on mycelial vegetative growth. Yeastlike cell counts were statistically similar for the wild-type isolate AU55-3 and the TOPA mutants $(P=0.7906)$. However, when liquid cultures of the same age were compared in the early growth phase $(48 \mathrm{~h})$, more daughter cells remained attached to the mother cells in mutant TOPA1 than in the wild-type isolate AU55-3. (Fig. 1D). No significant reduction of linear vegetative growth was observed in the mutants $(P=0.1739)$ (Table 2$)$.

Altered genes in TOPA mutants regulate DHN-melanin genes: scytalone feeding and RT-PCR. Feeding experiments with scytalone were carried out on PDA for the four $O$. piceae mutants (Fig. 1E). When the mutants were grown in the proximity of the C. lagenarium scd1 $1^{-}$mutant $9201 \mathrm{Y}$, which lacks scytalone dehydratase, or on media supplemented with purified scytalone (data not shown), melanin production in the mutants was restored or increased.

We used real-time RT-PCR to determine the effect of the identified insertional mutations on the expression of PKS1 and OSD1 genes from the DHN-melanin pathway (Table 3). In all four mu-

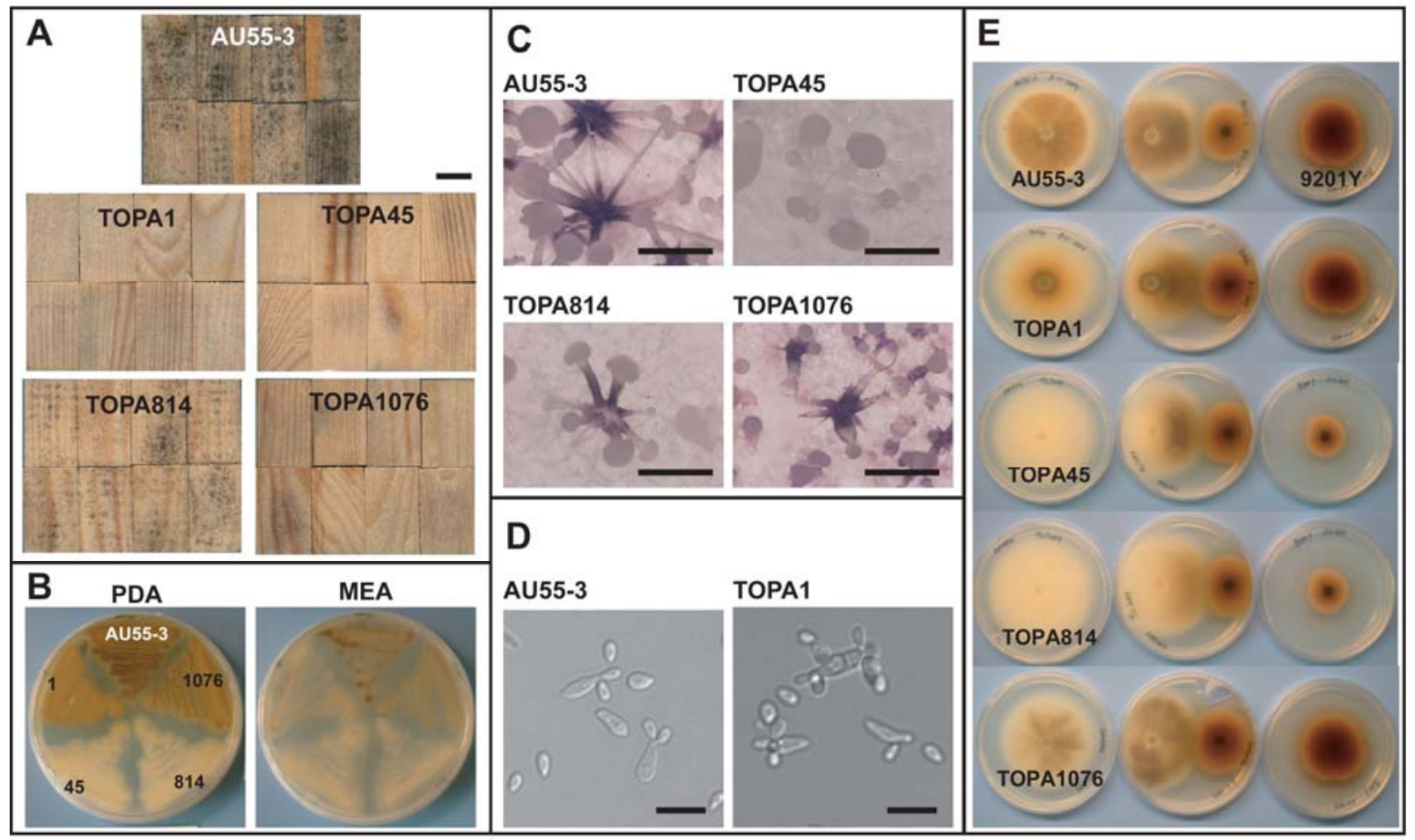

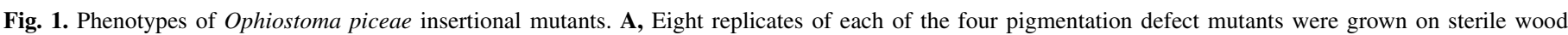

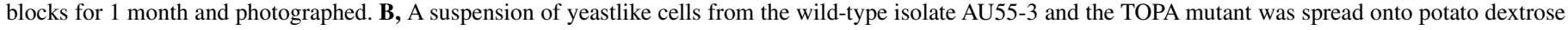

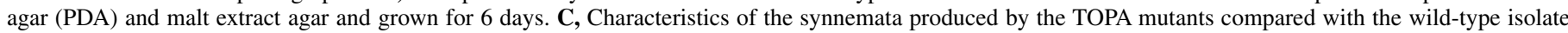

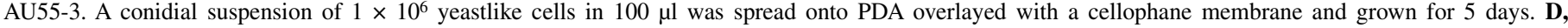

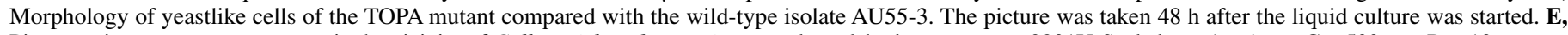
Pigmentation mutants were grown in the vicinity of Colletotrichum lagenarium scytalone dehydratase mutant $9201 \mathrm{Y}$. Scale bars: $\mathrm{A}=1 \mathrm{~cm} ; \mathrm{C}=500 \mu \mathrm{m} ; \mathrm{D}=10 \mu \mathrm{m}$. 
tants, the expression level of the $P K S 1$ gene was at least threefold lower than in the wild type. Expression levels of the OSDI gene were twofold lower in three mutants but 60-fold higher in the albino TOPA1 mutant compared with the wild type.

Linkage analysis. To confirm that the observed phenotypes were linked to the insertion loci, mutants were crossed with the sexually compatible $O$. piceae wild-type isolate AU123-142 and ascospores were collected at the tips of the oozing perithecia. In all, $\approx 80$ progeny from each cross were examined for the segregation of the hygromycin resistance marker and the mutant pigmentation phenotype. Co-segregation was observed for all mutants except TOPA814. In co-segregation work, it is important to validate that ascospores were analyzed rather than contaminating parental conidia. During the course of this study, we observed that, when crossed with isolate AU123-142, isolate AU55-3 and all TOPA mutants derived from it were female sterile. Consequently, all the sexual progeny, including those with mutant phenotypes, should have inherited their mitochondrial DNA from AU123-142. In contrast, single-spore isolates from contaminating parental conidia should have inherited mitochondrial DNA from AU55-3. To distinguish the mitochondrial DNA of isolates AU553 and AU123-142, we PCR amplified and sequenced the mitochondrial cytochrome $b$ gene with primers E1M and E2, as described by Wang (54). Two nucleotide polymorphisms were found between the two isolates. One of the polymorphisms permitted using the NdeI restriction enzyme to distinguish the two isolates by PCR-restriction fragment length polymorphism (RFLP). For each of the crosses AU123-142 $\times$ TOPA1, AU123-142 $\times$ TOPA45, AU123-142 × TOPA814, and AU123-142 × TOPA1076, two single-spore isolates with the mutant phenotype and two single-spore isolates with the wild-type phenotype were analyzed using the mitochondrial PCR-RFLP marker. All isolates had the AU123-142 mitochondrial DNA, indicating that they originated from ascospores rather than from contaminating parental conidia (Fig. 2).

Transgene copy number. Southern blot analysis was consistent with the integration of a single copy of T-DNA in each of the four mutants (Fig. 3). TOPA1 and TOPA45 were generated with plasmid pBHt2, which has one EcoRI site in its T-DNA. The hybridizing bands varied in size because they included the fulllength hygromycin resistance cassette, the T-DNA left border (LB), and adjacent $O$. piceae genomic DNA. Mutants TOPA814 and TOPA1076 were transformed with plasmid pAD1625 (1), which has two EcoRI sites in the T-DNA, and so showed two hybridizing bands. The 2.3-kbp band included most of the hygromycin resistance gene and the $\operatorname{trp} C$ terminator, while the second band in each transformant represented a junction fragment that includes the $c p c-1$ promoter, the T-DNA right border, and adjacent $O$. piceae genomic DNA.

Analysis of T-DNA integration. In order to obtain insight into the mechanism of T-DNA integration in $O$. piceae, we analyzed TDNA and $O$. piceae genomic DNA junctions and genomic preinsertion sites of the TOPA mutants. The genomic region flanking the right border (RB) of each T-DNA insert were obtained by inverse PCR and sequenced. Based on the results of the sequence analysis of inverse PCR amplicons, a set of primers was designed to amplify the RB flanking sequence of each mutant. The ge- nomic DNA of the wild-type isolate AU55-3 was amplified with these primers. The resulting amplicons were used to screen and isolate clones from a lambda genomic library and hybridizing clones were sequenced by primer walking. Except for TOPA45, the LB and their flanking genomic DNA were obtained by PCR using a primer from the $\mathrm{LB}$ and a primer from the lambda genomic clones. TOPA45 LB was obtained by inverse PCR. The right end of the T-DNA was retained up to the cleavage site in two out of four mutants (Fig. 4A). TOPA1 and TOPA1076 showed deletions of one and nine nucleotides of the RB repeat, respectively. Nucleotides from the LB repeat were found in all T-DNA junctions investigated. However, the LB was retained up to the cleavage site in mutant TOPA1 only. Deletions of 11 to $42 \mathrm{bp}$ were observed in the other left T-DNA junctions analyzed.

Genomic preinsertion target sites obtained from the lambda genomic library were compared with the T-DNA insertion loci data obtained from sequence analysis of inverse PCR amplicons. A schematic representation of the results is shown in Figure 4B. In TOPA1, T-DNA insertion triggered a deletion of $19 \mathrm{bp}$ with an inversion of $507 \mathrm{bp}$ next to the left end of the T-DNA. We observed that the inverted sequence was flanked by short palindromic repeats present in the wild-type progenitor. A recombination involving at least 3,500 bp occurred at the T-DNA insertion locus in TOPA45. Because none of the phages contained a sequence similar to that at the junction of the left end of T-DNA that we obtained by inverse PCR, we were unable to determine how many base pairs were involved in this recombination. In TOPA814, the T-DNA was inserted with no genomic deletion at the target site. However, a 518-bp fragment was translocated from an unknown locus at the junction at the LB. In TOPA1076, a 34-bp deletion occurred in the genomic sequence of the target site.

Sequences of the insertion loci were compared with GenBank using BLASTX. In TOPA1, the T-DNA integrated 394 bp downstream from the start codon of a gene predicted to encode a 635 amino-acid protein that had $46 \%$ identity to the putative Aspergillus fumigatus BEM1 protein, and $38 \%$ identity to the Saccharomyces cerevisiae BEM1 protein. This protein is involved in cell polarity and morphogenesis in these two fungal species. Further analysis using the ScanPROSITE program revealed that the O. piceae BEM1 protein contained two Src homology 3 (SH3) domains and one Phox homology (PX) domain $(37,39)$.

In TOPA45, the sequence at the junction of the T-DNA RB was predicted to encode a protein with homology to the $C$. lagenarium polyketide synthase (PKS1). The flanking RB sequence data indicated that the T-DNA inserted into the PKS1 gene coding region at nucleotide 2,834 . The sequence at the junction of the TDNA LB had no significant similarity with sequences present in

TABLE 3. Relative level of 1,8 dihydroxynaphthalene-melanin gene transcripts in insertional mutants compared with the wild-type isolate AU55-3

\begin{tabular}{lcccc}
\hline Gene $^{z}$ & TOPA1 & TOPA45 & TOPA814 & TOPA1076 \\
\hline PKS1 & $0.03 \pm 0.003$ & $0.11 \pm 0.009$ & $0.32 \pm 0.031$ & $0.31 \pm 0.014$ \\
OSD1 & $60.7 \pm 2.372$ & $0.52 \pm 0.036$ & $0.24 \pm 0.027$ & $0.03 \pm 0.009$ \\
\hline
\end{tabular}

${ }^{\mathrm{z}}$ Relative expression, normalized to that of the endogenous $\beta$-tubulin reference and expressed relative to the wild-type isolate AU55-3. The relative level of the calibrator transcript is 1 .

TABLE 2. Description of Ophiostoma piceae pigmentation mutants created by Agrobacterium-mediated insertional mutagenesis

\begin{tabular}{|c|c|c|c|c|c|}
\hline Isolate & Insertion Ti plasmid & Sporulation $\left(\times 10^{9} \text { cells } / \mathrm{ml}\right)^{\mathrm{y}}$ & Growth $(\mathrm{mm} / \text { day })^{\mathrm{z}}$ & Tagged gene & GenBank accession no. \\
\hline AU55-3 & $\ldots$ & $1.32 \pm 0.76 \mathrm{a}$ & $6.2 \pm 0.29 \mathrm{a}$ & $\ldots$ & \\
\hline TOPA1 & $\mathrm{pBHt} 2$ & $1.05 \pm 0.43 \mathrm{a}$ & $5.91 \pm 0.4 \mathrm{a}$ & BEM1 & EF125795 \\
\hline TOPA45 & $\mathrm{pBHt} 2$ & $1.64 \pm 0.89 \mathrm{a}$ & $6.3 \pm 0.11 \mathrm{a}$ & $P K S 1$ & EF125796 \\
\hline TOPA814 & pAD1625 & $1.48 \pm 0.72 \mathrm{a}$ & $6.03 \pm 0.28 \mathrm{a}$ & PIG1 & EF125798 \\
\hline TOPA 1076 & pAD1625 & $1.16 \pm 0.76 \mathrm{a}$ & $6.2 \pm 0.19 a$ & Unknown & EF125797 \\
\hline
\end{tabular}

\footnotetext{
${ }^{y}$ Mean values \pm standard deviations followed by the same letter are not significantly different at $P=0.05$. Conidiogenesis assessed in three replicate cultures.
}

${ }^{z}$ Colony diameters were measured after 3 and 10 days of growth on malt extract agar (Oxoid). Mean values are from five replicates. 
the GenBank nr database. The nucleotide sequence corresponding to the $\mathrm{RB}$ contained an open reading frame (ORF) that encoded a putative protein of 2,178 amino acids. The deduced amino acid sequence of $O$. piceae PKS1 shares 67\% identity with PKS1 of C. lagenarium (43), 68\% identity with PKS1 of a Nodulisporium sp. (18), $63 \%$ identity with PKS1 of C. resinifera (31), and $58 \%$ identity with PKS1 of Glarea lozoyensis (58). Like other polyketide synthases involved in DHN-melanin biosynthesis, the $O$. piceae PKS1 protein had four potential catalytic modules: $\beta$ ketoacyl synthase, an acyltransferase, two acyl carrier sites, and a thioesterase/Claisen cyclase.

In TOPA1076, the T-DNA integrated $438 \mathrm{bp}$ downstream from the start codon of a gene predicted to encode a protein that shared $51 \%$ identity to the hypothetical Neurospora crassa protein NCU02779.3. Broad Institute genomic data for $N$. crassa show that the gene locus NCU02779.3 is close to the gene locus NCU02778.3, which encodes a mannosyl-oligosaccharide 1,2- $\alpha$ mannosidase. The ORFs spanned a region $\approx 4.5 \mathrm{kbp}$ long, were separated by $\approx 1.25 \mathrm{kbp}$, and had the same orientation. Additional sequencing of the original lambda phage clone from which the genomic sequence of TOPA1076 was obtained showed an ORF encoding a protein with similarity to the $N$. crassa mannosyloligosaccharide 1,2- $\alpha$-mannosidase. The two $O$. piceae ORFs spanned $\approx 4.0 \mathrm{kbp}$, were separated by $\approx 1 \mathrm{kbp}$, but were oriented in opposite directions (away from each other).

In TOPA814, the T-DNA integrated 474 bp upstream from the start codon of a predicted ORF that showed no identity with known proteins in the GenBank nr database. However, the DNA sequence translocated at the left-end junction of the T-DNA was predicted to encode a protein with identity to fungal transcription factors with $\mathrm{Zn}$ (II)2Cys6 binuclear cluster DNA-binding proteins. No genetic linkage was observed between the TOPA814 phenotype and the T-DNA insertion locus; therefore, we hypothesized that the sequence at the junction of the left end of the T-DNA had been translocated from its original locus, creating a deletion that was responsible for the TOPA814 mutant phenotype. This locus was called PIGI (for pigmentation-related gene 1). To verify this, we retrieved the putative $5^{\prime}$ and $3^{\prime}$ ends using Ambion RLM-Race and designed primers flanking the translocated sequence (Fig. 4B). Then, we PCR amplified the respective DNA sequences from the two wild-type isolates AU55-3 and AU123-142, as well as from the TOPA814 insertion mutant. We identified a deletion corresponding to the size of the translocated sequence at the LB of the T-DNA insertion. The DNA from 24 progeny originating from a genetic cross between TOPA814 and AU123-142 then was amplified using the same primers. The co-segregation between the mutant phenotype and the mutated locus is shown in Figure 5.

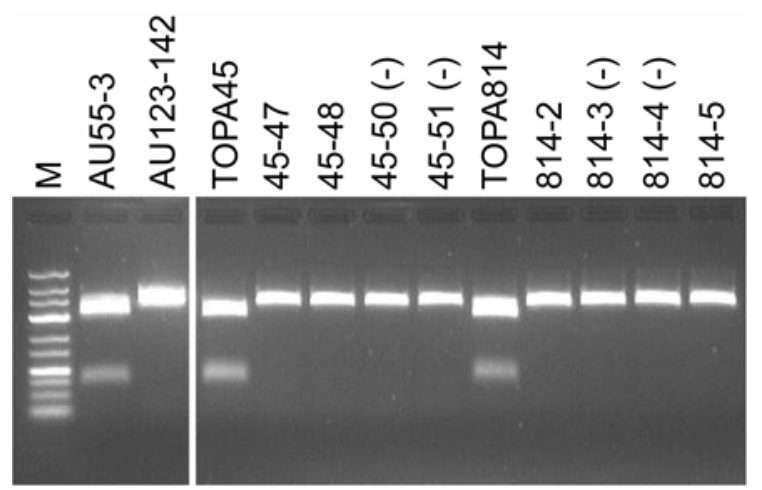

Fig. 2. Maternal inheritance of mitochondrial DNA in progeny obtained from genetic crosses TOPA45 $\times$ AU123-142 and TOPA814 $\times$ AU123-142. Polymerase chain reaction restriction fragment length polymorphism analysis of the mitochondrial cytochrome $b$ gene in four progeny per genetic cross, two progeny had the pigmentation-defect phenotype $(-)$. M = Fermentas GeneRuler lowrange ladder, bands are 25, 50, 75, 100, 150, 200, 300, 400, 500, and $700 \mathrm{bp}$.
To confirm that TOPA814 phenotype was caused by a deletion in the PIGl locus, we attempted to generate silencing constructs for both the PIGl gene and for the ORF corresponding to the TOPA814 T-DNA integration site. However, we were not able to obtain a silencing vector for PIG1, and silencing of AU55-3 with a construct containing sequences from the TOPA814 T-DNA integration site did not produce the TOPA814 phenotype. All transformants displayed pigmentation similar to the wild-type isolate AU55-3 (data not shown).
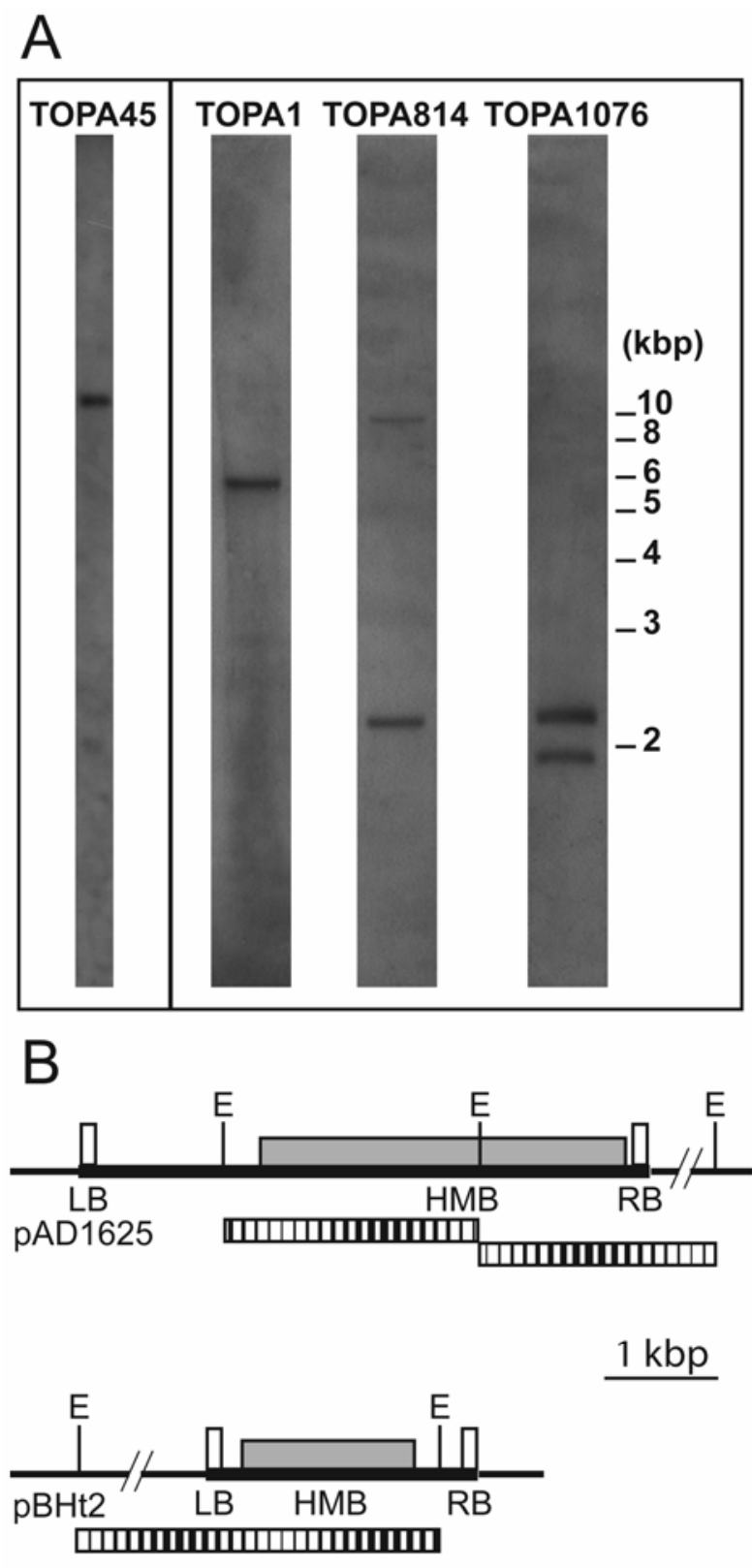

$1 \mathrm{kbp}$

Fig. 3. Southern blot analysis of T-DNA integration in the TOPA mutants. A, Genomic DNA was digested with EcoRI and probed with the 1.4-kbp HpaI fragment containing the hygromycin B (HMB) resistance cassette from plasmid pCB1004. The molecular marker on the right side of the figure indicates the molecular mass of the hybridizing bands for TOPA1, TOPA814, and TOPA1076. The hybridizing band of TOPA45 has a molecular mass of $\approx 7 \mathrm{kbp}$. B, Schematic representation of the integration of T-DNA from plasmids pAD1625 (1) and pBHt2 (38) in Ophiostoma piceae transformants. Thin lines represent the $O$. piceae genomic DNA and thick lines represent the T-DNA sequences. The left border (LB) and the right border (RB) are indicated by white boxes and the HMB by gray boxes. The EcoRI restriction site (E) are indicated. The variability of the EcoRI sites in the $O$. piceaeflanking sequence is represented by open bars. The hatched boxes below the maps indicate the size of the predicted hybridizing bands from the 1.4-kbp HMB probe. 


\section{DISCUSSION}

In this study, we isolated 30 mutants of $O$. piceae that had impaired growth or pigmentation. The mutants were identified by screening 2,136 transformants obtained by two insertional mutagenesis procedures: 1,053 by REMI and 1,083 by AMI. As we observed previously, a transgene was integrated at multiple loci in most REMI transformants but at a single locus in most AMI transformants (45). Because insertion of the transgene at a single locus facilitates identifying the gene responsible for a mutant phenotype, in this work we further characterized four $O$. piceae AMI transformants whose melanin production differed from the wild type.

We showed that TOPA45 had a mutant allele of the PKS1 gene. Type I fungal polyketide synthases (PKSs) synthesize secondary metabolites such as toxins and pigments (26). Our results indicated that the $P K S 1$ gene of $O$. piceae encodes a PKS protein that is essential for melanin biosynthesis. It previously was hypothesized that melanin is produced through the DHN pathway in the Ophiostoma fungi $(15,16,50-52,59)$. This hypothesis was formulated following previous studies that reported (i) biochemical complementation of an $O$. piliferum albino mutant by addition of scytalone (59), (ii) inhibition of melanin biosynthesis using specific inhibitors of DHN enzymes (16), and (iii) isolation of Ophiostoma DHN pathway genes and functional complementation of corresponding $M$. grisea and $C$. lagenarium mutants $(15,50,52)$. Our current work on insertional disruption of the $O$. piceae PKS1 gene supports these previous findings and reinforces the hypothesis that melanin is produced though the DHN pathway in Ophiostoma spp.

Melanin production is known to be a virulence factor in the phytopathogenic fungi $M$. grisea $(12,22)$ and C. lagenarium (27). However, in $O$. piceae TOPA45, fungal growth on solid media

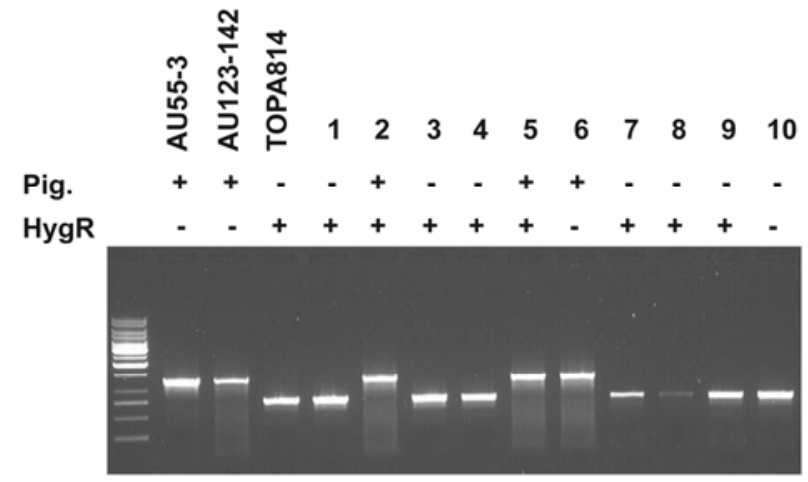

$\begin{array}{llllllllllllll}11 & 12 & 13 & 14 & 15 & 16 & 17 & 18 & 19 & 20 & 21 & 22 & 23 & 24\end{array}$

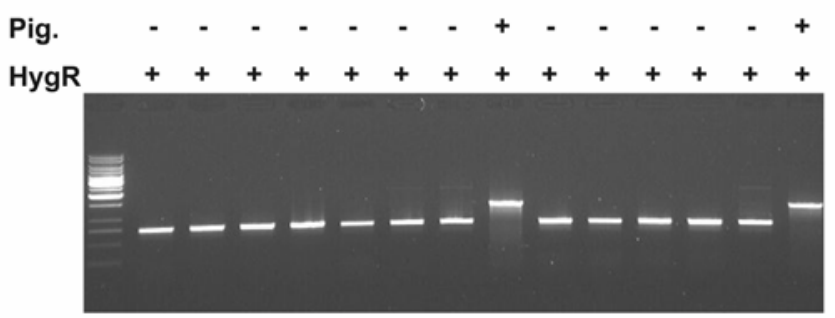

Fig. 5. Segregation of mutant phenotype, hygromycin $B$ resistance, and deletion at the PIG1 locus. The allele at the PIG1 locus was polymerase chain reaction amplified in wild-type isolates AU55-3 and AU123-142, in the TOPA814 mutant and in 24 progeny from a genetic cross between TOPA814 and AU123-142. The molecular weight marker is the GeneRuler 1-kb DNA ladder from Fermentas (Burlington, ON, Canada).

\section{A \\ B}
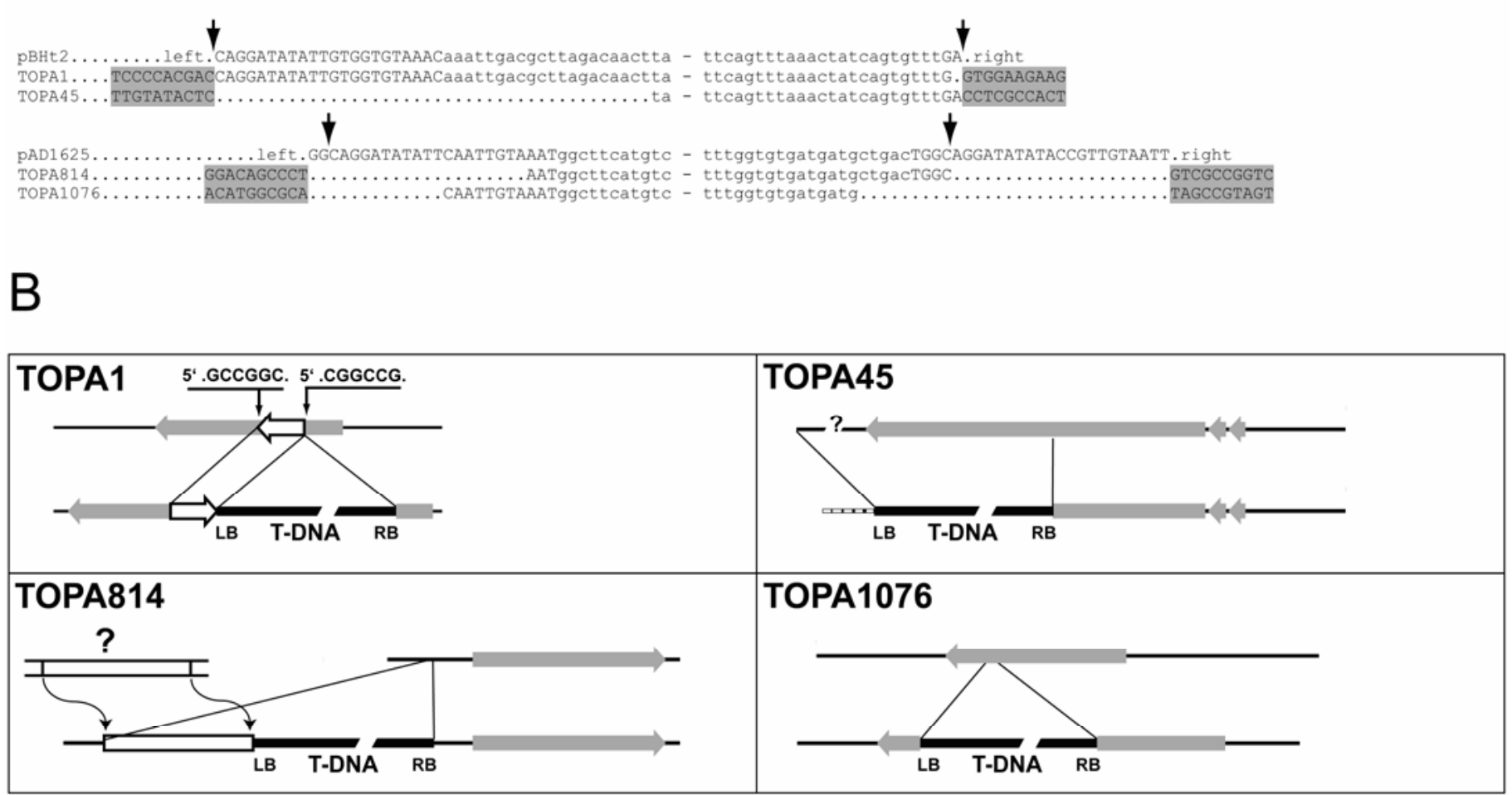

Fig. 4. Analysis of T-DNA integration sites in Ophiostoma piceae. A, Analysis of the integrated T-DNA border in the insertional $O$. piceae mutants. The nucleotide sequences from binary T-DNA plasmids pBHt2 and pAD1625 are shown followed by the nucleotide sequences of their respective insertional mutants. The T-DNA sequences are shown in normal type, the nucleotides belonging to the left and right T-DNA border repeats are uppercase, the arrows indicate the positions of the TDNA specific nicking, and the genomic sequences are shaded. B, Schematic organization of the target sites, comparison between the wild type and the insertional mutants. 
and in liquid culture remained comparable to the wild-type isolate AU55-3. Similar results were obtained for a Ceratocystis resinifera pks1- mutant $(31,46)$, a species with an ecological niche similar to $O$. piceae. We anticipate that melanin may have similar biological functions in these two species; however, this function remains to be determined.

As well as identifying an essential gene for DHN-melanin biosynthesis, genes also were identified that appeared to be involved in the transcriptional regulation of melanin production. In the insertional mutant TOPA1076, the T-DNA was integrated into a gene that encodes a protein whose function is unknown. This mutant was less pigmented than the wild type and its synnemata developed abnormally. The stipes of the synnemata were smaller than the wild type, and no conidiogenous cells were formed at the tip of the conidiophores. The reduction of pigmentation in TOPA1076 was associated with the downregulation of the PKSI and OSDI genes; these two DHN-melanin genes showed a 3- and 30-fold reduction, respectively, in expression compared with the wild type.

The TOPA1 insertion was in a gene encoding a protein with identity to the BEM1 protein of $S$. cerevisiae. In $S$. cerevisiae, BEM1 protein is involved in establishing cell polarity and morphogenesis. BEM1 functions as a scaffold protein for complexes that include CDC24, STE5, STE20, and RSR1 $(30,32)$. S. cerevisiae BEM1 homologs also have been characterized in other yeasts and filamentous fungi $(33,57)$. Morphological abnormalities were observed in Candida albicans and A. nidulans beml null mutants. Although the formation of buds and germ tubes was not completely inhibited, these morphological defects eventually resulted in cell damage and death. Morphological abnormalities of both yeastlike cells and hyphae also were observed in the O. piceae BEMI insertional mutant TOPA1, and its melanin production was reduced. In yeast, the SH3 domain of BEM1 physically binds to the $\mathrm{p} 21$ activated kinase STE20 to activate MAP kinase signaling cascades (55). It is possible that, in $O$. piceae, melanin biosynthesis may be regulated through MAP kinase pathways that are activated by BEM1/STE20. The Colletotrichum lagenarium MAP kinase CMK1, homolog of $S$. cerevisiae FUS3/KSS1, was found to control expression of the melanin genes PKS1 and SCD1 during conidial germination (42). However, unlike $O$. piceae, C. lagenarium mycelial melanization was not affected by the dysfunctional pheromone-activated MAP kinase pathway.

In addition to pigmentation defects, mutants TOPA1 and TOPA1076 showed abnormal conidiophore development. These results suggested a close relationship between fungal development and melanin production. Such a relationship has been characterized in Aspergillus mutants showing defects in conidiation and toxin production (56).

Finally, mutant TOPA814 resulted from a deletion into the PIGl gene which encodes a protein with identity to fungusspecific Zn(II)2Cys6 binuclear cluster proteins. Such proteins are transcription factors that are found only in fungi but control a wide range of metabolic processes, including secondary metabolite synthesis. For example, the transcription factor AflR regulates the biosynthesis of aflatoxin and sterigmatocystin in Aspergillus spp. (56). In Glarea lozoyensis, the PKS1 gene is involved in DHN-melanin biosynthesis and may be regulated by the $d g s$ gene, which encodes a putative Zn(II)2Cys6 binuclear cluster DNAbinding protein and is physically linked with the PKS1 gene (58). However, the function of DGS has not been determined and its involvement in melanin regulation remains speculative. At this time, the only evidence that transcription factors with a $\mathrm{Zn}$ (II)2Cys6 binuclear cluster motif regulate melanin production comes from the phytopathogenic fungi $C$. lagenarium and $M$. grisea (48). In these fungi, hyphal melanization is regulated by CMR1 and PIG1, respectively.

Fungal regulatory proteins of the $\mathrm{Zn}$ (II)2Cys6 binuclear cluster family have three functional domains: (i) a $\mathrm{Zn}$ (II)2Cys6 binuclear cluster, which is involved in DNA binding; (ii) a middle homology region, which may be necessary for in vivo DNA binding specificity (40), and (iii) a less-well-understood activation domain (6). However, unlike the above examples, the PIG1 protein had only the middle homology region (MHR), which the Pfam Protein Families Database indicates is a domain that is specific to fungal transcription factors (Fungal_trans; Pfam04082). This result contradicts the observation of Schjerling and Holmberg (40), who reported that the MHR domain was confined to Zn(II)2Cys6 binuclear cluster proteins. GenBank database searches revealed that several hypothetical proteins from filamentous fungi contained only the MHR domain; however, at this time, none of these proteins have been characterized. We note that the Leptosphaeria maculans gene $L m Z n F 3$ encodes a protein that contains the MHR domain, and the sequence of this gene is clustered with LmPKS1 of the melanin pathway (19).

In this work, we also characterized the mode of integration of the T-DNA in $O$. piceae. We successfully obtained the T-DNA junction fragments at either side of the T-DNA in the four TOPA mutants. Sequence analysis showed that up to $42 \mathrm{bp}$ of the T-DNA border was deleted. Truncations at the LB of the T-DNA were found more frequently than at the RB junction. Similar results have been reported for plants and other fungi. This suggests a pattern of T-DNA integration similar to what was described in plants, and supports the model of T-DNA integration in which the LB inserts at a target site before the RB $(8,13,47)$.

In plants, a wide diversity of chromosomal defects (generated upon T-DNA integration) has been described, ranging from singlebase mutations to large chromosomal translocations $(11,20,29)$. Whereas, in T-DNA-transformed fungi, only small deletions have been reported $(23,35)$, in the present work with $O$. piceae we describe two rearrangements: an inversion at the LB of the TDNA in the TOPA1 mutant, and a translocation at the LB of the TDNA in the TOPA814 mutant.

The rearrangements we describe can be detected only by sequencing the flanking DNA from both T-DNA borders and analyzing their origins in the genome; in our TOPA814 mutant, these did not correspond to the same genomic locus. A few cases of rearrangement following T-DNA integration in a fungal genome have been reported but not characterized $(35,49)$. Such rearrangements may be common. However, they could be overlooked routinely because, in sexually reproducing fungi, a segregation test typically is performed before retrieving the T-DNA flanking sequences, and mutants in which the phenotype and the selection marker do not co-segregate usually are not further characterized $(23,49)$.

Concluding remarks. Although sapstaining fungi are widespread and reduce the value of wood products, little is understood about the melanization process in these fungi. For $O$. piceae, because high-throughput functional analyses were not available, we used insertional mutagenesis to identify pigmentation-related genes. Our results showed that Agrobacterium-mediated insertional mutagenesis is effective for tagging genes relevant to pigmentation in $O$. piceae, despite frequently causing genome rearrangement, and revealed novel aspects of regulation in DHNmelanin biosynthesis. The method is simple and robust, and could be used to generate a larger insertional mutagenesis library of O. piceae that would yield further insight into the melanization process in sapstaining fungi.

\section{ACKNOWLEDGMENTS}

This work was supported by a grant from the Natural Sciences and Engineering Research Council of Canada (NSERC) to C. Breuil. P. Tanguay was the recipient of a postgraduate scholarships from the Fonds Québécois de la Recherche sur la Nature et les Technologies, and a University Graduate Fellowship from University of British Columbia. We thank R. Philippe and P. Chan for their excellent technical assistance, S. 
Kang and J. N. Galgiani for kindly providing the binary Ti plasmids, and $\mathrm{M}$. Wheeler for donating a sample of scytalone.

\section{LITERATURE CITED}

1. Abuodeh, R. O., Orbach, M. J., Mandel, M. A., Das, A., and Galgiani, J. N. 2000. Genetic transformation of Coccidioides immitis facilitated by Agrobacterium tumefaciens. J. Infect. Dis. 181:2106-2110.

2. Bell, A. A., Puhalla, J. E., Tolmsoff, W. J., and Stippanovic, R. D. 1976. Use of mutants to establish (+)-scytalone as an intermediate in melanin biosynthesis by Verticillium dahliae. Can. J. Microbiol. 22:787-799.

3. Bell, A. A., and Wheeler, M. H. 1986. Biosynthesis and functions of fungal melanins. Annu. Rev. Phytopathol. 24:411-451.

4. Bernier, L., and Hubbes, M. 1990. Meiotic analysis of induced mutations in Ophiostoma ulmi. Can. J. Bot. 68:232-235.

5. Bernier, L., and Hubbes, M. 1990. Mutations in Ophiostoma ulmi induced by N-methyl-N'-nitro-N-nitrosoguanidine. Can. J. Bot. 68:225-231.

6. Borkovich, K. A., Alex, L. A., Yarden, O., Freitag, M., Turner, G. E., Read, N. D., Seiler, S., Bell-Pedersen, D., Paietta, J., Plesofsky, N., Plamann, M., Goodrich-Tanrikulu, M., Schulte, U., Mannhaupt, G., Nargang, F. E., Radford, A., Selitrennikoff, C., Galagan, J. E., Dunlap, J. C., Loros, J. J., Catcheside, D., Inoue, H., Aramayo, R., Polymenis, M., Selker, E. U., Sachs, M. S., Marzluf, G. A., Paulsen, I., Davis, R., Ebbole, D. J., Zelter, A., Kalkman, E.R., O'Rourke, R., Bowring, F., Yeadon, J., Ishii, C., Suzuki, K., Sakai, W., and Pratt, R. 2004. Lessons from the genome sequence of Neurospora crassa: Tracing the path from genomic blueprint to multicellular organism. Microbiol. Mol. Biol. Rev. 68:1-108.

7. Brasier, C. M., and Kirk, S. A. 1993. Sibling species within Ophiostoma piceae. Mycol. Res. 97:811-816.

8. Bundock, P., and Hooykaas, P. 1996. Integration of Agrobacterium tumefaciens T-DNA in the Saccharomyces cerevisiae genome by illegitimate recombination. Proc. Natl. Acad. Sci. USA 93:15272-15275.

9. Butler, M., and Day, A. 1998. Fungal melanins: A review. Can. J. Microbiol. 44:1115-1136.

10. Carroll, A., Sweigard, J., and Valent, B. 1994. Improved vectors for selecting resistance to hygromycin. Fungal Genet. Newslett. 41:22.

11. Castle, L. A., Errampalli, D., Atherton, T. L., Franzmann, L. H., Yoon, E. S., and Meinke, D. W. 1993. Genetic and molecular characterization of embryonic mutants identified following seed transformation in Arabidopsis. Mol. Gen. Genet. 241:504-514.

12. Chumley, F. G., and Valent, B. 1990. Genetic analysis of melanindeficient nonpathogenic mutants of Magnaporthe grisea. Mol. PlantMicrobe Interact. 3:135-143.

13. de Groot, M. J., Bundock, P., Hooykaas, P. J., and Beijersbergen, A. G. 1998. Agrobacterium tumefaciens-mediated transformation of filamentous fungi. Nat. Biotechnol. 16:839-842.

14. Eagen, R., Brisson, A., and Breuil, C. 1997. The sap-staining fungus Ophiostoma piceae synthesizes different types of melanin in different growth media. Can. J. Microbiol. 43:592-595.

15. Eagen, R., Kim, S. H., Kronstad, J. W., and Breuil, C. 2001. An hydroxynaphthalene reductase gene from the wood-staining fungus Ophiostoma floccosum complements the buff phenotype in Magnaporthe grisea. Mycol. Res. 105:461-469.

16. Fleet, C., and Breuil, C. 2002. Inhibitors and genetic analysis of scytalone dehydratase confirm the presence of DHN-melanin pathway in sapstain fungi. Mycol. Res. 106:1331-1339.

17. Fleet, C., Breuil, C., and Uzunovic, A. 2001. Nutrient consumption and pigmentation of deep and surface colonizing sapstaining fungi in Pinus contorta. Holzforschung 55:340-346.

18. Fulton, T. R., Ibrahim, N., Losada, M. C., Grzegorski, D., and Tkacz, J. S. 1999. A melanin polyketide synthase ( $P K S$ ) gene from Nodulisporium sp. that shows homology to the PKS1 gene of Colletotrichum lagenarium. Mol. Gen. Genet. 262:714-720.

19. Gardiner, D. M., Cozijnsen, A. J., Wilson, L. M., Pedras, M. S. C., and Howlett, B. J. 2004. The sirodesmin biosynthetic gene cluster of the plant pathogenic fungus Leptosphaeria maculans. Mol. Microbiol. 53:13071318.

20. Gheysen, G., Villarroel, R., and Van Montagu, M. 1991. Illegitimate recombination in plants: A model for T-DNA integration. Genes Dev. 5:287-297.

21. Hemingway, R. W., McGraw, G. W., and Barras, S. J. 1977. Polyphenols in Ceratocystis minor infected Pinus taeda: Fungal metabolites, phloem and xylem phenols. J. Agric. Food Chem. 25:717-722.

22. Howard, R. J., Ferrari, M. A., Roach, D. H., and Money, N. P. 1991. Penetration of hard substrates by a fungus employing enormous turgor pressures. Proc. Natl. Acad. Sci. USA 88:11281-11284.

23. Idnurm, A., Reedy, J. L., Nussbaum, J. C., and Heitman, J. 2004. Cryptococcus neoformans virulence gene discovery through insertional mutagenesis. Eukaryotic Cell 3:420-429.
24. Kahmann, R., and Basse, C. 1999. REMI (restriction enzyme mediated integration) and its impact on the isolation of pathogenicity genes in fungi attacking plants. Eur. J. Plant Pathol. 105:221-229.

25. Kihara, J. 2004. Studies on photomorphogenesis in a phytopathogenic fungus induced by near-ultraviolet radiation. J. Gen. Plant Pathol. 70:388.

26. Kroken, S., Glass, N. L., Taylor, J. W., Yoder, O. C., and Turgeon, B. G. 2003. Phylogenomic analysis of type I polyketide synthase genes in pathogenic and saprobic ascomycetes. Proc. Natl. Acad. Sci. USA 100:15670-15675.

27. Kubo, Y., Suzuki, K., Furusawa, I., and Yamamoto, M. 1982. Effect of tricyclazole on appressorial pigmentation and penetration from appressoria of Colletotrichum lagenarium. Phytopathology 72:1198-1200.

28. Kubo, Y., Suzuki, K., Furusawa, I., and Yamamoto, M. 1983. Scytalone as a natural intermediate of melanin biosynthesis in appressoria of Colletotrichum lagenarium. Exp. Mycol. 7:208-215.

29. Laufs, P., Autran, D., and Traas, J. 1999. A chromosomal paracentric inversion associated with T-DNA integration in Arabidopsis. Plant J. 18:131-139.

30. Leeuw, T., Fourest-Lieuvin, A., Wu, C., Chenevert, J., Clark, K., Whiteway, M., Thomas, D. Y., and Leberer, E. 1995. Pheromone response in yeast: Association of Bem1p with proteins of the MAP kinase cascade and actin. Science 270:1210-1213.

31. Loppnau, P., Tanguay, P., and Breuil, C. 2004. Isolation and disruption of the melanin pathway polyketide synthase gene of the softwood deep stain fungus Ceratocystis resinifera. Fungal Genet. Biol. 41:33-41.

32. Madden, K., and Snyder, M. 1998. Cell polarity and morphogenesis in budding yeast. Annu. Rev. Microbiol. 52:687-744.

33. Michel, S., Ushinsky, S., Klebl, B., Leberer, E., Thomas, D., Whiteway, M., and Morschhauser, J. 2002. Generation of conditional lethal Candida albicans mutants by inducible deletion of essential genes. Mol. Microbiol. 46:269-280.

34. Michielse, C. B., Hooykaas, P. J., van den Hondel, C. A., and Ram, A. F. 2005. Agrobacterium-mediated transformation as a tool for functional genomics in fungi. Curr. Genet. 48:1-17.

35. Michielse, C. B., Ram, A. F. J., Hooykaas, P. J. J., and van den Hondel, C. A. M. J. J. 2004. Agrobacterium-mediated transformation of Aspergillus awamori in the absence of full-length $\mathrm{VirD} 2$, VirC2, or VirE2 leads to insertion of aberrant T-DNA structures. J. Bacteriol. 186:2038-2045.

36. Möller, E., Bahnweg, G., Sandermann, H., and Geiger, H. 1992. A simple and efficient protocol for isolation of high molecular weight DNA from filamentous fungi, fruit bodies, and infected plant tissues. Nucleic Acids Res. 20:6115-6116.

37. Morton, C. J., and Campbell, I. D. 1994. SH3 domains. Molecular 'Velcro'. Curr. Biol. 4:615-617.

38. Mullins, E. D., Chen, X., Romaine, P., Raina, R., Geiser, D. M., and Kang, S. 2001. Agrobacterium-mediated transformation of Fusarium oxysporum: An efficient tool for insertional mutagenesis and gene transfer. Phytopathology 91:173-180.

39. Ponting, C. P. 1996. Novel domains in NADPH oxidase subunits, sorting nexins, and PtdIns 3-kinases: Binding partners of SH3 domains? Protein Sci. 5:2353-2357.

40. Schjerling, P., and Holmberg, S. 1996. Comparative amino acid sequence analysis of the C6 zinc cluster family of transcriptional regulators. Nucleic Acids Res. 24:4599-4607.

41. Seifert, K. A. 1993. Sapstain of commercial lumber by species of Ophiostoma and Ceratocystis. Pages 141-151 in: Ceratocystis and Ophiostoma: Taxonomy, Ecology, and Pathogenicity. M. J. Wingfield, K. A. Seifert, and J. F. Webber, eds. The American Phytopathological Society, St. Paul, MN.

42. Takano, Y., Kikuchi, T., Kubo, Y., Hamer John, E., Mise, K., and Furusawa, I. 2000. The Colletotrichum lagenarium MAP kinase gene CMK1 regulates diverse aspects of fungal pathogenesis. Mol. PlantMicrobe Interact. 13:374-383.

43. Takano, Y., Kubo, Y., Shimizu, K., Mise, K., Okuno, T., and Furusawau, I. 1995. Structural analysis of $P K S 1$, a polyketide synthase gene involved in melanin biosynthesis in Colletotrichum lagenarium. Mol. Gen. Genet. 249:162-167.

44. Tanguay, P., Bozza, S., and Breuil, C. 2006. Assessing RNAi frequency and efficiency in Ophiostoma floccosum and O. piceae. Fungal Genet. Biol. 46:804-812.

45. Tanguay, P., and Breuil, C. 2003. Transforming the sapstaining fungus Ophiostoma piceae with Agrobacterium tumefaciens. Can. J. Microbiol. 49:301-304.

46. Tanguay, P., Loppnau, P., Morin, C., Bernier, L., and Breuil, C. 2006. A spontaneous albino mutant of Ceratocystis resinifera results from a point mutation in the polyketide synthase gene, PKS1. Can. J. Microbiol. 52:501-507.

47. Tinland, B. 1996. The integration of T-DNA into plant genomes. Trends Plant Sci. 1:178-184.

48. Tsuji, G., Kenmochi, Y., Takano, Y., Sweigard, J., Farrall, L., Furusawa, I., Horino, O., and Kubo, Y. 2000. Novel fungal transcriptional activators, 
Cmr1p of Colletotrichum lagenarium and pig1p of Magnaporthe grisea, contain Cys2His2 zinc finger and Zn(II)2Cys6 binuclear cluster DNAbinding motifs and regulate transcription of melanin biosynthesis genes in a developmentally specific manner. Mol. Microbiol. 38:940-954.

49. Walton, F. J., Idnurm, A., and Heitman, J. 2005. Novel gene functions required for melanization of the human pathogen Cryptococcus neoformans. Mol. Microbiol. 57:1381-1396.

50. Wang, H. L. 2002. Characterization of scytalone dehydratase and reductase genes and expression of melanin biosynthesis genes in Ophiostoma floccosum. Ph. D. thesis, Wood Sciences, University of British Columbia, Vancouver, Canada.

51. Wang, H. L., and Breuil, C. 2002. A second reductase gene involved in melanin biosynthesis in the sap-staining fungus Ophiostoma floccosum. Mol. Gen. Genomics 267:557-563.

52. Wang, H. L., Kim, S. H., and Breuil, C. 2001. A scytalone dehydratase gene from Ophiostoma floccosum restores the melanization and pathogenicity phenotypes of a melanin-deficient Colletotrichum lagenarium mutant. Mol. Gen. Genomics 266:126-132.

53. Wang, H. L., Kim, S. H., Siu, H., and Breuil, C. 1999. Transformation of sapstaining fungi with hygromycin B resistance plasmids pAN7-1 and pCB1004. Mycol. Res. 103:77-80.

54. Wang, L., Yokoyama, K., Miyaji, M., and Nishimura, K. 1998. The identification and phylogenetic relationship of pathogenic species of Aspergillus based on the mitochondrial cytochrome b gene. Med. Mycol. 36:153-164.
55. Winters, M. J., and Pryciak, P. M. 2005. Interaction with the SH3 domain protein Bem1 regulates signaling by the Saccharomyces cerevisiae p21activated kinase Ste20. Mol. Cell. Biol. 25:2177-2190.

56. Yu, J. H., and Keller, N. 2005. Regulation of secondary metabolism in filamentous fungi. Annu. Rev. Phytopathol. 43:437-458.

57. Zarrin, M., Leeder, A. C., and Turner, G. 2005. A rapid method for promoter exchange in Aspergillus nidulans using recombinant PCR. Fungal Genet. Biol. 42:1-8.

58. Zhang, A., Lu, P., Dahl-Roshak, A. M., Paress, P. S., Kennedy, S., Tkacz, J. S., and An, Z. 2003. Efficient disruption of a polyketide synthase gene $(p k s 1)$ required for melanin synthesis through Agrobacteriummediated transformation of Glarea lozoyensis. Mol. Genet. Genomics 268:645-655.

59. Zimmerman, W. C., Blanchette, R. A., Burnes, T. A., and Farrell, R. L. 1995. Melanin and perithecial development in Ophiostoma piliferum. Mycologia 87:857-863.

60. Zink, P., and Fengel, D. 1988. Studies on the colouring matter of bluestain fungi. Part 1. General characterization and the associated compounds. Holzforschung 42:217-220.

61. Zink, P., and Fengel, D. 1989. Studies on the colouring matter of bluestain fungi. Part 2. Electron microscopic observations of the hyphae walls. Holzforschung 43:371-374.

62. Zink, P., and Fengel, D. 1990. Studies on the colouring matter of bluestain fungi. Part 3. Spectroscopic studies on fungal and synthetic melanins. Holzforschung 44:163-168. 